\title{
The Basics of a National Health Information System in Dentistry
}

\author{
Bazele unui sistem informatic naţional în stomatologie
}

\author{
Claudia-Gabriela Mateiaş, Alexandru-Titus Farcaşiu, Mihaela Păuna \\ Facultatea de Medicină Dentară, Universitatea de Medicină şi Farmacie „Carol Davila“, Bucureşti, România
}

\begin{abstract}
National Health Information Systems are a widely accepted concept as a step forward for improving health ser-vices. In their simplest form, Health Information Systems are represented through Electronic Health Records (EHR) and offer a standardized storage and retrieval environment for patient information including personal data, case history, diagnostics and treatments. Such a system needs to be easy to access and use, sure, stable and standardized. Accessibility can be enhanced by using the internet to provide connectivity from anywhere and from any environment to the central database; ease of use is created by the intuitive and simplified interface. Security and stability are provided by the implementation of internationally accepted security protocols and the choice of a non-vulnerable database and operating system. Standardization is created by introducing international systems design standards, as well as diagnostic and treatment codes. Used nationally (and in the nearby future, internationally), the systems may contribute to research and development of new treatments and standardizing current practices.
\end{abstract}

Keywords: health information systems, data base, electronic health record

\section{REZUMAT}

Sistemele informatice naţionale sunt un concept acceptat la scară largă ca fiind un pas înainte pentru îmbunătăţirea serviciilor de sănătate. În cea mai simplă formă, sisteme informatice sunt prezentate sub forma fişelor medicale electronice (FME) şi oferă un mediu de stocare standardizată şi de recuperare a informaţiilor pacienţilor cuprinzând date personale, date despre antecedentele pacienţlor, diagnostice şi tratamente. Un astfel de sistem trebuie sa fie uşor de accesat şi de utilizat, sigur, stabil şi standardizat. Accesibilitatea poate fi îmbunătăţită prin folosirea internetului pentru a oferi posibilitatea conectării de oriunde şi de pe orice mediu la baza de date centrală; uşurinţa utilizării este creată prin interfaţa intuitivă şi simplificata. Siguranţa şi stabilitatea sunt date de implementarea de protocoale de securitate acceptate la nivel internaţional şi de alegerea unui sistem de baze de date şi de operare nevulnerabil. Standardizarea este creată prin introducerea standardelor internaţionale de concepere a sistemelor, dar şi a codurilor de diagnostice şi tratament. Utilizate naţional (şi într-un viitor apropiat, internaţional), aceste sisteme pot contribui la cercetarea şi dezvoltarea de noi tratamente şi la standardizarea practicilor curente.

Cuvinte cheie: sistem informatic naţional, baza de date, fişa medicală electronică

\section{INTRODUCERE}

Sistemele informatice medicale sunt implementate sub forma fişelor medicale electronice. Fişele medicale electronice au fost clasificate pe baza Organizaţiei Internaţionale a Standardelor (ISO) ca fiind o colecţie de informaţii în formă computerizată referitoare la starea sănătăţii unui pacient, stocată şi transmisă în deplină siguranţă şi accesibilă oricărui utilizator autorizat. Are ca scop principal asigurarea continuă, eficientă şi de calitate a serviciilor de sănătate integrate şi conţine informaţii retrospective, concurente şi prospective (1).

Astfel de sisteme sunt din ce în ce mai utilizate în cadrul practicilor medicale în ţări europene ca: Austria (din 2012), Danemarca (care nu are sisteme la scara naţională, ci multiple sisteme locale interconectate), Estonia (prima ţară din lume care a implementat un sistem naţional de fişe medicale în 2008), dar şi extra-european, în particular in Statele Unite ale Americii. 
În România, există multiple sisteme de evidenţă a pacienţilor, sisteme care au utilizare restrânsă, puţine pot fi interconectate şi care sunt folosite ca fişe medicale electronice, în principal în sectorul privat. Alternativ, sistemul creat de Casa Naţională de Asigurări de Sănătate, denumit Sistemul Informatic Unic Integrat al CNAS, extins cu Sistemele Informatice pentru Prescripţia Electronică şi Cardul Electronic de Asigurări de Sănătate (SIUI + SIPE + CEAS), este un sistem creat pentru a ţine evidenţa tratamentelor în conjucţie cu bugetul alocat fiecărui asigurat, interfaţa pentru medici fiind de nivel rudimentar, dar cu o parte administrativă complexă. Acest sistem poate fi folosit naţional, dar scopul este de a administra sumele alocate pacienţilor asiguraţi, platforma nefiind utilizabilă pentru cercetare, dezvoltare şi nu este conform legislaţiei europene (7).

General Data Protection Regulations (GDPR) sunt un set de reguli de arhitectură securizată care trebuie urmate de toate sistemele care conţin date cu caracter personal şi care a intrat în vigoare de la 25 mai 2018 (10). Consimţământul capătă un rol esenţial deoarece pacienţii trebuie să fie înştiinţaţi de procesarea datelor lor şi să fie conştienţi de drepturile lor (e.g. dreptul la acces, dreptul la retragerea din sistem şi ştergerea tuturor datelor, dreptul la partajarea datelor, dreptul de a restricţiona datele etc.). Securitatea trebuie să fie implementată din designul sistemului prin: tehnici de pseudoanonimizare, transparenţă pentru funcţiile şi procesarea datelor, permiterea monitorizării accesului la propriile date, posibilitatea de a crea şi îmbunătăţi etapele de securitate.

Premisele unui sistem informatic naţional în stomatologie se regăsesc în nevoia unei platforme clare şi coerente care să poată fi folosită de către toţi medicii şi pacienţii şi care va îmbunătăţi calitatea îngrijirilor medicale. Sistemul trebuie să îndeplinească nevoia de a înregistra şi analiza un volum tot mai mare de date medicale şi posibilitatea de a partaja datele medicale între medici de diferite specialităţi.

O premisă importantă se regăseşte şi în directivele europene de E-sănătate, cea mai importantă dintre ele fiind Planul de acţiune privind e-sănătatea 2012-2020 - Asistenţă medicală inovatoare pentru secolul XXI (2). Planul oferă linii de ghid pentru pacienţi, cadrele medicale şi alţi lucrători în domeniul sănătaţii să asocieze dispozitive şi tehnologii şi să investească în medicina personalizată a viitorului.

Scopul acestui sistem este împărtăşit de multiple proiecte (3):

1. nevoia de memorare structurată a datelor medicale în vederea accesării rapide şi în condiţii de securitate de oriunde;

2. nevoia definirii informaţiilor esenţiale ale acestor fişe;

3. alegerea şi implementarea de standarde, nomenclatoare, coduri şi vocabulare;

4. nevoia dezvoltării infrastructurii şi politicilor de securitate;

5. dezvoltarea de sisteme deschise, standardizate şi interoperabile pentru partajare de date şi managementul informaţiilor;

6. implicarea pacienţilor în utilizarea propriilor fişe medicale.

\section{METODE. PROIECTAREA SISTEMULUI}

Proiectarea sistemului a început cu schematizarea infrastructurii bazei de date şi suprastructurii interfeţei şi s-a ţinut cont de 5 elemente cheie: uşurinţa accesului, uşurinta utilizării (cât de user-friendly este interfaţa), stabilitatea sistemului, siguranţa datelor şi standardizarea sistemului.

Baza de date este infrastructura sistemului: date colectate organizate în scheme, tabele, rapoarte, proceduri, pachete, secvenţe etc. Baza de date are rolul de a capta, stoca şi analiza informaţia şi securizare.

Interfaţa este suprastructura sistemului şi este o aplicaţie web dezvoltată pentru a asigura interacţiunea cadrelor medicale şi pacienţilor cu baza de date.

\section{Uşurința accesului}

Majoritatea programelor de evidenţă a pacienţilor solicită instalare pe computerul medicului, programele fiind operabile numai în contextul deschiderii computerului şi programului; pacientii pot primi copii printate sau copii digitale pe mail ale fişelor medicale completate.

Sistemul creat are baza de date situată pe un server într-o locaţie la distanţă, iar accesul bazei de date se va face prin internet de pe orice orice mediu mobil (tabletă, smartphone, laptop) sau imobil (PC) prin intermediul interfeţei web. Aplicaţia web este 
dezvoltată folosind ORACLE Application Express datorită flexibilităţii, simplităţii şi gratuităţii. $\mathrm{Cu}$ ajutorul ei, interfaţa este sub forma unei pagini web, accesată printr-un URL de pe orice browser, neţinând cont de sistemul de operare al utilizatorului şi fără a instala ceva pe client. Medicul poate înregistra pacienţi de pe orice mediu (Mac, Android, Windows etc.) atât timp cât are o conexiune la internet şi un browser web funcţional.

Pacienţii îşi pot accesa pagina prin aceeaşi metodă prin username-ul şi parola generată unde pot vedea fişa completată şi consimţământul. Figura 1 schematizează modalitatea de acces şi fluxul de informaţii din sistem.

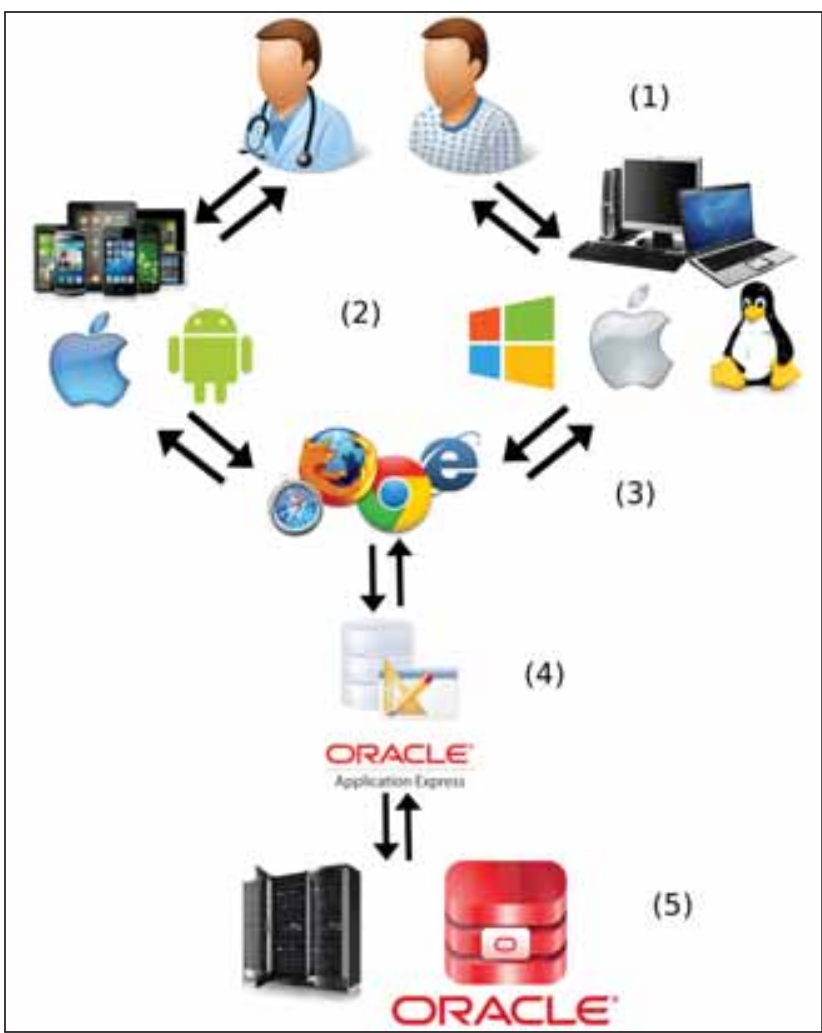

FIGURA 1. Accesul şi fluxul de informații. (1) Medicii şi pacienții, utilizatori de $P C$, tablete, smart-phone cu diferite sisteme de operare (2), se conectează la internet prin browser (3) pentru a accesa baza de date (5) prin intermediul interfeței web (4).

\section{Uşurința utilizării}

Utilizatorii majoritari vor fi medici stomatologi, aşadar designul interfeţei trebuie sa fie cât mai familiar şi cât mai intuitiv pentru acest group de utilizatori. Fişa unui pacient va fi conform fişei medicale standard şi la prima înregistrare va cuprinde: informaţii personale, motivul prezentării, antecedente personale ereditare şi patologice, istoric, examen clinic general, local şi oral, diagnostic pre- zumptiv, diagnostic final şi plan de tratament. După înregistrare, câmpurile necompletate nu vor fi vizibile pentru a nu încărca dosarul cu elemente care nu sunt necesare. Pentru a spori eficienţa completării fişei, medicul poate accesa numai un anumit set de întrebări din anamneză. De exemplu, dacă un pacient se prezintă pentru durere dentară, fără nicio plângere la nivel muscular/articular, setul de întrebări din categoria „Tulburări temporo-mandibulare“" poate fi ignorat. Categorizarea întrebărilor va spori satisfacţia pentru sistem deoarece este uşor de navigat şi nu se pierde timp valoros din anamneză.

\section{Stabilitatea sistemului}

Un sistem stabil este un sistem predictibil, testat şi care nu este predispus la erori sau este suficient de robust pentru a face faţă erorii respective fără să înceteze să funcţioneze; un sistem stabil trebuie să fie capabil să facă faţă atât factorilor locali de stres (e.g căderi accidentale de tensiune), cât şi stresului provocat de atacurile din internet (e.g autoblocare pentru protecţia datelor generală sau pe username depinzând de tipul atacului).

Stabilitatea acestui sistem este dată de baza de date şi de sistemul de operare pe care este instalată aceasta. Sistemul de operare al serverului este Linux CentOS 7 şi a fost ales deoarece nu este vulnerabil la breşe de securitate, este testat şi actualizat (versiunea este cea mai nouă şi este susţinută de dezvoltatori până în 2024), pentru securitate, eficienţă şi viteza ridicată (aspect foarte important în cazul unei cantităţi mari de date) (4).

Baza de date este de tip ORACLE XE 11 g, bază de date relaţională şi a fost aleasă pentru viteza mare de execuţie, vulnerabilitatea scăzută şi capacitatea mare de înmagazinare a datelor.

\section{Siguranța sistemului}

Siguranţa poate fi privită din două puncte de vedere:

1) Locaţia în care este plasat serverul trebuie să fie sigură şi cu acces la internet;

2) Dezvoltarea aplicaţiei trebuie sa aibă în vedere tot ceea ce este necesar pentru protecţia datelor din baza de date, care, în general, sunt date foarte sensibile.

Pentru a realiza sistemul din punct de vedere practic, se pot folosi schemele clasice de realizare în care fiecare modul de bază se află pe câte un 


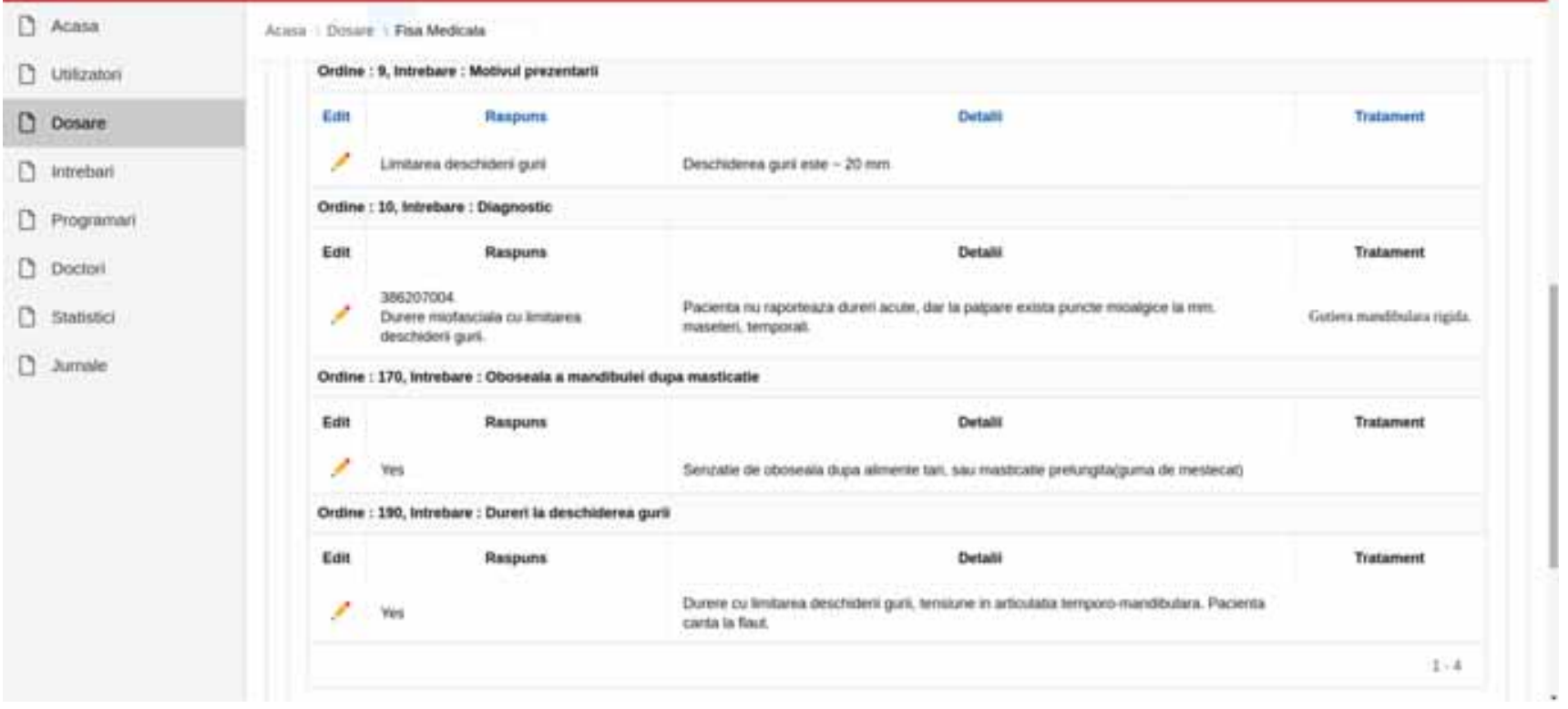

FIGURA 2. Exemplu de fişă medicală completată

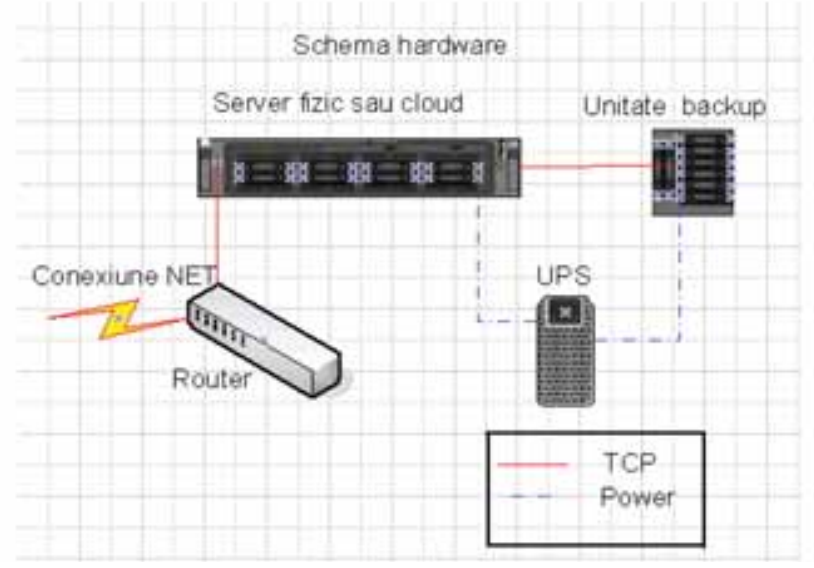

FIGURA 3. Schema hardware a sistemului

server distinct sau, aşa cum s-a decis în cazul de faţă, se pot utiliza scheme moderne pe un cloud privat, iar modulele sunt realizate pe maşini virtuale.

Sistemul este alimentat cu energie electrică printr-un UPS care îl protejează de căderile accidentale de tensiune sau de creşterile de tensiune peste limitele standard. De asemenea, este prevăzut cu o unitate de back-up cu ajutorul căreia se va crea o politica de back-up şi recuperare pentru a garanta siguranţa datelor. Sistemul este conectat la internet printr-un router în care există un firewall care ajută la protecţia împotriva atacurilor externe.

În Fig. 4. se observă cele trei maşini virtuale (VM) de bază: VM DMZ, VM ORACLE DB, VM Mail Server, care sunt conectate la maşina virtuală firewall. Aceasta asigură securitatea şi protecţia datelor ce se găsesc pe celelalte maşini virtuale. Ma-

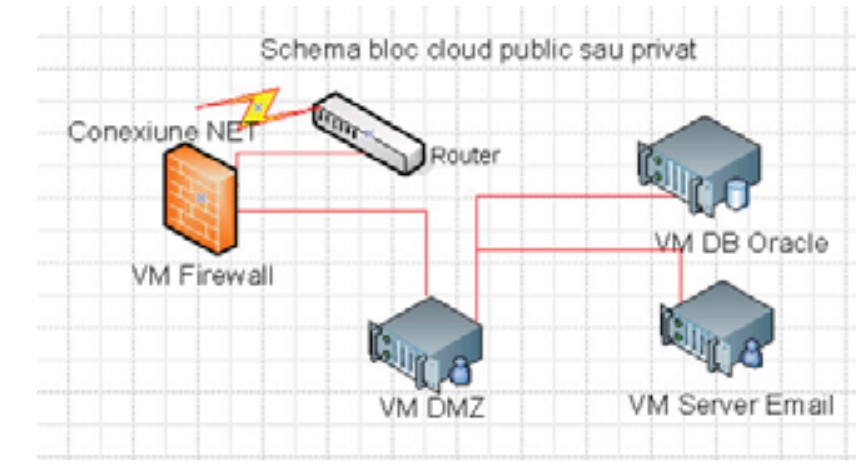

FIGURA 4. Schema modulurilor din bloc cloud

şina virtuală DMZ (demilitarized zone) va găzdui serverul de nume, serverul web şi serverul de relay mail. Acest server asigură legatura aplicaţiei cu internetul şi nu va conţine date pentru a preveni spargerea şi preluarea datelor. Maşina virtuală ORACLE DB este maşina care asigură funcţionarea bazei de date, dar şi a aplicaţiei. Orice aplicaţie care lucrează în internet are nevoie şi de un server de email care permite clienţilor să transmită sau să primească emailuri.

Sistemul foloseşte tehnici de pseudoanonimitate (procesul prin care datele de identificare sunt scoase sau modificate pentru ca identitatea să nu fie descoperită). În esenţă, toţi cei care vor să aibă acces la informaţiile pacienţilor (e.g. cercetători) nu vor vedea datele personale ale pacienţilor. O altă etapă în securizarea sistemului este criptarea, etapă care este făcută la nivel de sistem de operare şi de 
bază de date şi cheia de criptare este păstrată de administrator.

Accesul în baza de date este supravegheat prin tehnici de autentificare (utilizator/parolă) şi prin tehnici de controlare a accesului prin atribuire de roluri (RBAC - role based access control) în care fiecare utilizator are anumite privilegii în funcţie de rolul sau. Medicul poate vedea fişele tuturor pacienţilor săi, pacientul poate vedea numai fişa proprie, cercetătorii pot vedea numai datele ne-personale ale pacienţilor şi statistica efectuată de sistem.

Un aspect important în siguranţa sistemului este înregistrarea accesului la fişe (auditing) pentru ca administratorul să poată verifica accesul şi pentru ca pacientul să vadă ce medic i-a accesat dosarul şi dacă acesta a modificat vreo informaţie. Aspect important şi pentru îmbunătăţirea autodeterminării pacientului, acesta devine implicat în propria fişă.

Toate aceste elemente sunt în linie cu cerinţele internaţionale de securitate pentru sisteme informatice medicale (5), aspect important de precizat deoarece cele mai multe preocupări ale utilizatorilor (medici şi pacienţi) sunt în legătură cu securitatea (8). Sistemele vechi, cu multe dependenţe de sistemul de operare Microsoft Windows (e.g sistemul casei de sănătate), sunt foarte greu de securizat în internet. Din punct de vedere GDPR, sistemele vechi nu corespund.

\section{Standardizarea sistemului}

Standardizarea sistemului se reflectă în eficienţa sistemului (cu cât este mai standard, cu atât este mai simplu de utilizat şi mai uşor de interfaţat cu alte sisteme şi mai uşor de adăugat noi facilităţi în dezvoltare), în siguranţa lui (prin implementarea de măsuri de securitate minime în funţie de rolul utilizatorului în aplicaţie) şi în posibilitatea folosirii datelor în cercetare.

Standardizarea sistemului a început prin crearea unei liste de diagnostice care să permită medicului să selecteze direct diagnosticul fără să mai fie nevoie să îl scrie, eliminând problemele impuse de lipsa de consecvenţă din variantele de text liber. Sistemul va fi îmbunătăţit prin crearea listelor pentru tratamente, semne, simptome etc. şi prin clasificarea lor utilizând coduri internaţionale (International Classification of Diseases ICD, Systemized Nomenclature of Medicine SNOMED).

\section{REZULTATE ŞI DISCUŢII}

Sistemul este funcţional şi în continuă dezvoltare. În momentul de faţă, administratorul poate crea acces medicilor/cercetătorilor, iar medicii pot crea acces pacienţilor. Fişa medicală conţine minimumul de informaţii, i se pot adăuga imagini, este accesibilă prin internet şi uşor de utilizat. Sistemul, deşi este la început, are implementate bazele de securitate şi stabilitate.

În principal, fundamentul unui astfel de sistem începe de la securitate, de la regulile necesare pentru a asigura securitatea sistemului şi de la legislaţia de protecţie a datelor cu caracter personal. Legislaţia urmată este legislaţia europeană sub forma normelor GDPR.

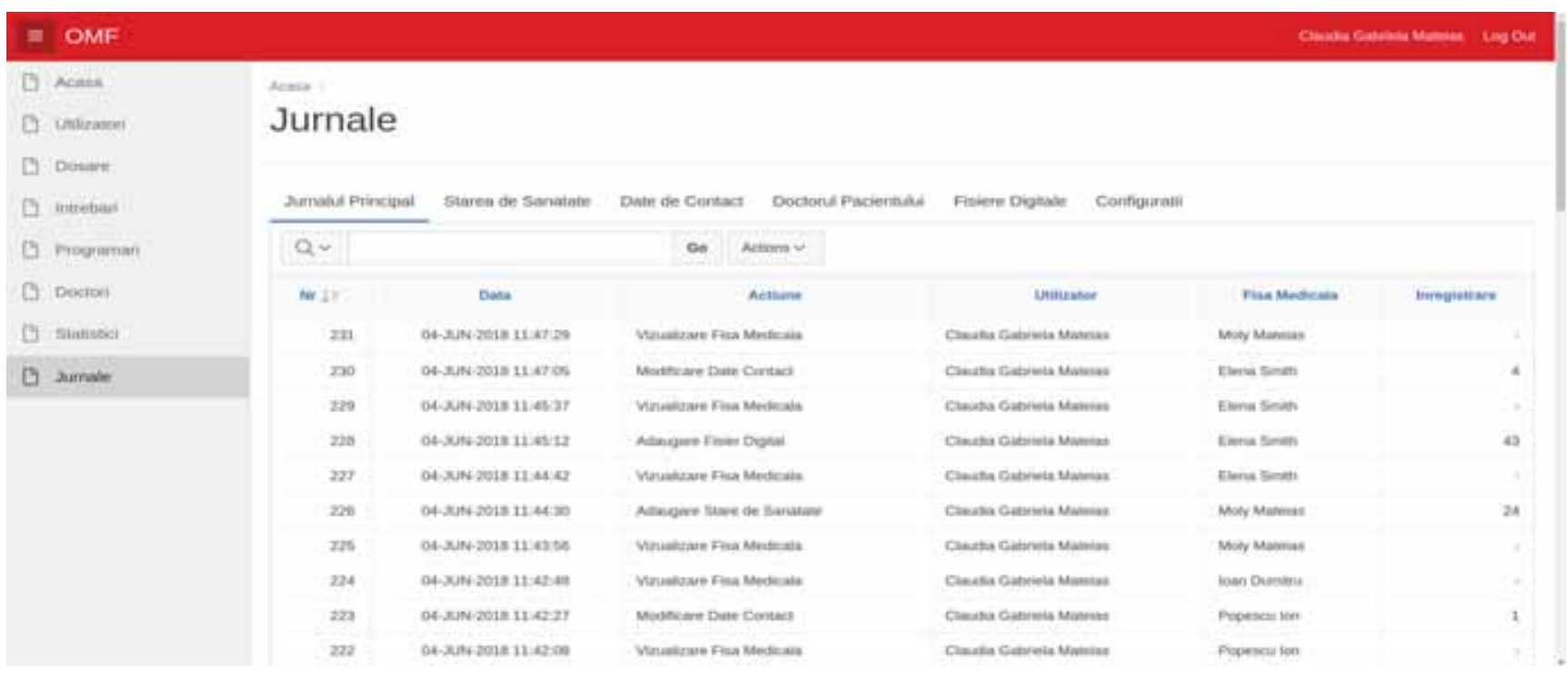


Consimţământul va apărea în scris în fişa pacientului, la prima vizită medicul îl va citi, iar pacientul va lua cunoştinţă de ceea ce presupune procesarea datelor. Consimţământul este clar, cu opţiune de refuz pentru fiecare aspect al sistemului (e.g. pentru stocare de date/pentru participare la statistică etc.), uşor de retras (implicit cu ştergerea tuturor datelor) şi la îndemâna pacientului de fiecare dată când va accesa fişa.

Accesul la informaţie este înregistrat şi accordat numai persoanelor autorizate. Procedurile de detecţie, raportare şi investigare a accesului incorect (data breach) sunt îndeplinite în procedura de auditing. O altă regulă este desemnarea unui responsabil de protecţie a datelor, în acest caz acest rol îl are administratorul bazei de date.

Sistemul se află în momentul de faţă pe un server privat, dar, la final, va fi portat în ORACLE Cloud şi va beneficia de toate măsurile de securitate de care dispune acest servici.

Un aspect care trebuie considerat este costul. Sistemul de operare al serverului (Linux CentOs 7), baza de date (ORACLE XE $11 \mathrm{~g}$ ) şi aplicaţia interfeţei (ORACLE Application Express) sunt gratuite, dar în continuă dezvoltare şi, mai ales, în continuă utilizare, sistemul va trebui extins. Costurile vor cuprinde extindere de software (schimbarea bazei de date de la ORACLE XE 11g la ORACLE XE 12c, portarea în Cloud), de hardware, de personal care să ofere suport tehnic. O altă resursă importantă este timpul: finalizarea sistemului (e.g. adăugarea codurilor ICD şi SNOMED) şi extinderea lui vor dura.

Un alt motiv pentru care s-a ales dezvolarea sistemului după arhitectura prezentata este versatilitatea în implementarea unor noi opţiuni, de exemplu, un modul pentru tehnician (care să ofere o cale de co- municare între acesta şi medic) sau un modul pentru departamentul financiar. În aceeaşi ordine de idei, versatilitatea este importantă şi în condiţiile în care vor fi impuse noi metode de a îmbunătăţi securitatea.

Pentru a evita problemele impuse de eroarea umană trebuie să existe documentaţie privind utilizarea sistemului atât pentru medici, cât şi pentru pacienţi (6), idee care va fi adăugată odată ce sistemul este în forma finală. Documentaţia va fi critică în adopţia sistemului, deoarece percepţia unui sistem de această natură are aceeaşi importanţă asemeni calităţii sistemului (9).

Unul dintre cele mai importante puncte de vorbit este legislaţia naţională. Ultimul raport al comisiei europene pe acest domeniu este din 2014, unde comisia a conclus că nu există legislaţie specifică pentru fişele medicale electronice şi că ceea ce există nu acoperă ce date să fie incluse în fişe, cerinţele pe care trebuie să le îndeplinească instituţiile care utilizează sistemele, accesul şi actualizarea sistemelor, răspunderea, utilizarea secundară (e.g. pentru cercetare) (7).

\section{CONCLUZII}

Un sistem informatic în stomatologie corect construit şi securizat este complementar activităţii medicului şi benefic pentru autodeterminarea pacienţilor. Proiectul propus este în faza intermediară, poate fi utilizat şi i se adaugă noi idei în fiecare săptămână pentru a optimiza cât mai mult procesul de introducere/stocare/recuperare a datelor. Bazele unui sistem informatic în stomatologie se regăsesc în liniile de ghid create de regulile europene şi internaţionale de funcţionalitate a tuturor sistemelor informatice medicale.

Conflict of interest: none declared Financial support: none declared

\section{BIBLIOGRAFIE}

1. ISO/DTR 20514, Health Informatics, Electronic Health Record, Definition, Scope and Context, 2004.

2. https://ec.europa.eu/health/sites/health/files/ehealth/docs/ com_2012_736_en.pdf accesat in mai 2018.

3. Häyrinen $\bar{K}$., Saranto K., Nykänen P. Definition, structure, content, use and impacts of electronic health records: $A$ review of the research literature. Int. J. Med. Inf. 2008; 77(5):291-304.

4. https://www.futurehosting.com/blog/the-advantages-anddisadvantages-of-centos/ accesat in mai 2018.

5. Fernández-Alemán J.L., Carrión Sr.I., Lozoya P.A.O., Toval A. ecurity and privacy in electronic health records: A systematic literature review J. Biomed. Inform. 2013; 46(3):541-62.
6. Kierkegaard P. Electronic health record: Wiring Europe's healthcare Computer 7Law \& Security Report 2011; 27(5):503-515.

7. https://ec.europa.eu/health//sites/health/files/ehealth/docs/ laws_romania_en.pdf accesat in mai 2018.

8. Entzeridou E., Markopoulou E., Mollaki V. Public and physician's expectations and ethical concerns about electronic health record: Benefits outweigh risks except for information security Int. J. Med. Inf. 2018; 110:97-10.

9. Miller R.H., Sim I. Physicians' Use Of Electronic Medical Records: Barriers And Solutions Health Aff. 2004; 23(2):116-26.

10. https://www.eugdpr.org/ accesat în mai 2018. 